\title{
Ostium Ratio and Neck Ratio Could Predict the Outcome of Sidewall Intracranial Aneurysms Treated with Flow Diverters
}

(D) N. Paliwal, (D).M. Tutino, (D) H. Shallwani, DJ.S. Beecher, (D).J. Damiano, DH.J. Shakir, (D) G.S. Atwal, (D) V.S. Fennell, (D).K. Natarajan, (D)E.I. Levy, (D)A.H. Siddiqui, (D).M. Davies, and (D) H. Meng

\begin{abstract}
BACKGROUND AND PURPOSE: Incompletely occluded flow diverter treated aneurysms remain at risk of rupture and thromboembolic complications. Our aim was to identify the potential for incomplete occlusion of intracranial aneurysms treated by flow diverters. We investigated whether aneurysm ostium size in relation to parent artery size affects angiographic outcomes of flow diverter-treated sidewall aneurysms.
\end{abstract}

MATERIALS AND METHODS: Flow diverter-treated sidewall aneurysms were divided into "occluded" and "residual" (incomplete occlusion) groups based on 6-month angiographic follow-up. We calculated the ostium ratio, a new parameter defined as the aneurysm ostium surface area versus the circumferential surface area of the parent artery. We also calculated the neck ratio, defined as clinical aneurysm neck diameter versus parent artery diameter from pretreatment 2D DSA, as a 2D surrogate. We compared the performance of these ratios with existing aneurysm morphometrics (size, neck diameter, volume, aspect ratio, size ratio, undulation index, nonsphericity index, ellipticity index, bottleneck factor, aneurysm angle, and parent vessel angle) and flow diverter-related parameters (metal coverage rate and pore density). Statistical tests and receiver operating characteristic analyses were performed to identify significantly different parameters between the 2 groups and test their predictive performances.

RESULTS: We included 63 flow diverter-treated aneurysms, 46 occluded and 17 residual. The ostium ratio and neck ratio were significantly higher in the residual group than in the occluded group $(P<.001$ and $P=.02$, respectively), whereas all other parameters showed no statistical difference. As discriminating parameters for occlusion, ostium ratio and neck ratio achieved areas under the curve of 0.912 ( $95 \%$ $\mathrm{Cl}, 0.838-0.985)$ and $0.707(95 \% \mathrm{Cl}, 0.558-0.856)$, respectively.

CONCLUSIONS: High ostium ratios and neck ratios could predict incomplete occlusion of flow diverter-treated sidewall aneurysms. Neck ratio can be easily calculated by interventionists to predict flow-diverter treatment outcomes.

ABBREVIATIONS: CND = clinical neck diameter; FD = flow diverter; $M C R=$ metal coverage rate; NR = neck ratio; OsR = ostium ratio; VSW = virtual stenting workflow

Clow diverters (FDs) are used to treat an increasing diversity of intracranial aneurysms. ${ }^{1-3}$ These devices are self-expanding, densely braided metallic stents that are deployed across the aneu-

Received June 21, 2018; accepted after revision November 7.

From the Department of Mechanical and Aerospace Engineering (N.P., R.J.D., H.M.), Canon Stroke and Vascular Research Center (N.P., V.M.T., R.J.D., E.I.L., A.H.S., J.M.D., H.M.), and Department of Biomedical Engineering (V.M.T., H.M.), University at Buffalo, Buffalo, New York; Departments of Neurosurgery (V.M.T., H.S., J.S.B., H.J.S. G.S.A., V.S.F., S.K.N., E.I.L., A.H.S., J.M.D., H.M.), Radiology (E.I.L., A.H.S.), and Biomedical Informatics (J.M.D.), Jacobs School of Medicine, University at Buffalo, Buffalo, New York; Department of Neurosurgery (H.S., J.S.B., H.J.S., G.S.A., V.S.F., S.K.N., A.H.S., J.M.D.), Gates Vascular Institute at Kaleida Health, Buffalo, New York, and Jacobs Institute (A.H.S., J.M.D.), Buffalo, New York.

This work was supported by Canon Medical Systems Corporation and National Institutes of Health grant R01-NS-091075. J.M.D. was supported by the National Center for Advancing Translational Sciences of the National Institutes of Health under award number KL2TR001413 to the University at Buffalo.

The content is solely the responsibility of the authors and does not necessarily represent the official views of the National Institutes of Health. rysm neck. The goal of flow diversion is to reconstruct the parent artery by diverting blood flow from the aneurysm, subsequently initiating thrombus formation in the aneurysm sac and endothelialization across the parent vessel defect (ie, the ostium). Despite the success of this strategy, up to $15 \%$ of FD-treated aneurysms have incomplete thrombosis within the sac, ${ }^{4}$ meaning that a persistent risk for aneurysm rupture and further complications exists. $^{5,6}$

Physicians look to morphologic metrics to predict outcomes

Please address correspondence to Hui Meng, PhD, Canon Stroke and Vascular Research Center, Clinical Translational Research Center, 875 Ellicott St, Buffalo, NY 14214; e-mail: huimeng@buffalo.edu

- Indicates open access to non-subscribers at www.ajnr.org

$\equiv$ Indicates article with supplemental on-line appendix.

Indicates article with supplemental on-line photos.

http://dx.doi.org/10.3174/ajnr.A5953 
and tailor treatment. Our goal was to identify metrics that could be measured before treatment that may indicate potential incomplete occlusion of FD-treated aneurysms. For coil embolization, surgeons have used aneurysm dome and neck measurements to gauge treatment options. ${ }^{7,8}$ However, these metrics do not necessarily equate to success with flow diversion. Mut et $\mathrm{al}^{9}$ demonstrated that aneurysm neck diameter, size, volume, and aspect ratio do not indicate the occlusion outcome of FD-treated aneurysms. These parameters only consider measurements of the aneurysm sac and not the parent vessel or its relationship to the aneurysm. Gentric et $\mathrm{al}^{10}$ showed that flow-diversion effects vary with the size of the aneurysm ostium (ie, the defect in the parent artery made by the aneurysm). They also postulated that larger defects might cause deformation of the struts of the FD, affecting FD porosity across the aneurysmal defect, thus leading to ineffective flow diversion.

In this study, we hypothesized that the aneurysmal defect on the parent artery and the extent to which it circumferentially envelops the parent artery affect the ability of the FD to redirect flow away from the aneurysm and thus may reduce the likelihood of occlusion. To quantify this concept, we defined a novel parameter, ostium ratio (OsR), which is the ratio of the area of the ostium surface of the aneurysm to the circumferential parent vessel area. A 2D surrogate, the neck ratio (NR), was also defined as the ratio of the aneurysm neck diameter to the parent artery diameter. The OsR and NR were evaluated in 63 sidewall aneurysms treated with FDs. Forty-six aneurysms had complete occlusion, and 17 had residual filling on angiographic imaging at the 6-month follow-up. Other aneurysm morphometrics and FD parameters were also compared between the 2 groups. Linear regression analysis was performed to check for correlation of the OsR with FD parameters.

\section{MATERIALS AND METHODS}

\section{Patient Selection and Aneurysm Model Generation}

A data base of a consecutive series of patients with aneurysms treated using the Pipeline Embolization Device (Covidien, Irvine, California) has been maintained at the University at Buffalo. From this data base, we retrospectively identified patients treated between 2009 and 2017 who satisfied the inclusion criteria of our study. These criteria included the following: imaging evidence of a sidewall ICA aneurysm treated using a single Pipeline Embolization Device, no previous treatment of the aneurysm, pretreatment 3D rotational DSA images with sufficient quality for accurate reconstruction and segmentation for precise morphologic modeling, and 6-month 2D DSA follow-up available. We excluded previously treated aneurysms to avoid confounding of the healing due to the presence of an existing endovascular device with the healing associated with FD treatment. The pretreatment 3D DSA images were segmented using an open-source software package, Vascular Modeling Toolkit (www.vmtk.org), to obtain accurate surface representation of the vascular geometry of each aneurysm.

Approval for the collection and review of patient data was obtained from the institutional review board. Consent from the individual patients was waived by the board.
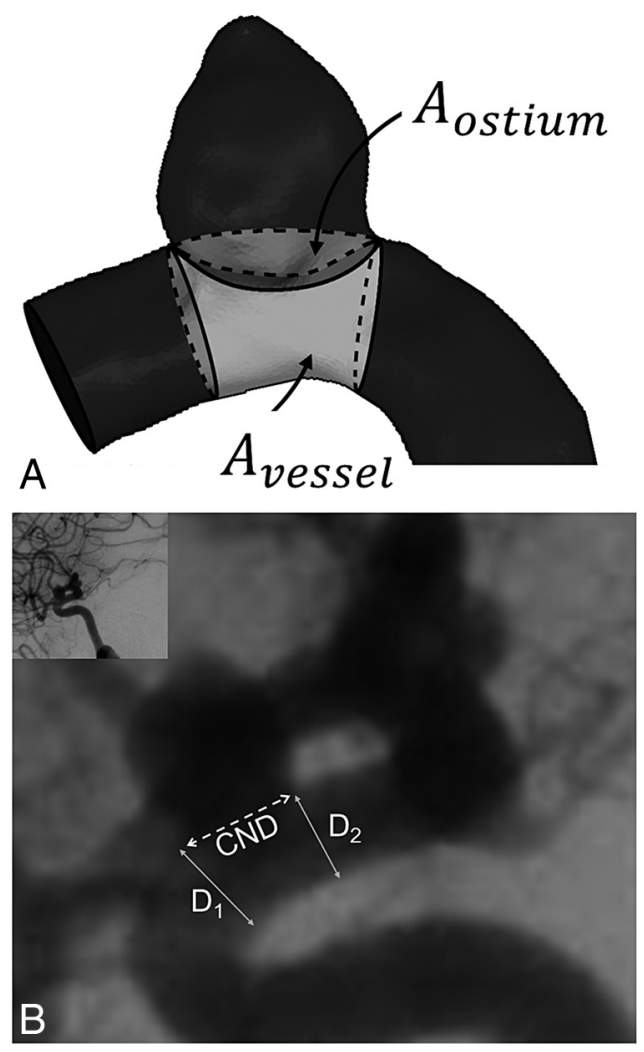

FIG 1. Definitions of OsR and NR on the 3D model and 2D DSA image for a representative patient-specific aneurysm. $A$, The illustration shows the area of the ostium surface (within the dashed curves) and the area of the circumferential parent artery (within the solid lines) for OsR calculations. B. CND and parent vessel diameters $\left(D_{1}, D_{2}\right)$ are calculated on the most perpendicular projection of the pretreatment 2D DSA imaging. $D_{1}$ and $D_{2}$ are measured at the proximal and distal extremes, respectively, of the line that measures the CND.

\section{Ostium Ratio}

The OsR was defined as the area of the reconstructed aneurysm ostium surface $\left(A_{\text {ostium }}\right)$ divided by the area of the circumferential section of the remaining parent vessel $\left(A_{\text {vessel }}\right)$. The circumferential section of the parent vessel was determined by drawing 2 planes at the proximal and distal extremities of the aneurysmal ostium surface in the parent vessel. Regions representing $A_{\text {ostium }}$ and $A_{\text {vessel }}$ are illustrated on a representative sidewall aneurysm in Fig $1 A$.

$$
O s R=\frac{A_{\text {ostium }}}{A_{\text {vessel }}}
$$

The ostium and parent vessel surfaces for calculating the OsR are obtained in 3 steps: parent vessel reconstruction, ostium surface generation, and corresponding parent vessel isolation. Details on each step for calculation of the OsR are described in the On-line Appendix.

\section{Neck Ratio}

Because complex computations of the 3D aneurysm geometry are required to calculate the OsR, we devised a surrogate, the NR, which can easily be calculated by interventionists. The NR is the ratio of the clinical neck diameter (CND) to the average parent vessel diameter. To obtain this ratio, we used pretreatment $2 \mathrm{D}$ 
angiographic images, and the image with the most perpendicular projection was identified for each aneurysm. Then, CND and the proximal $\left(D_{1}\right)$ and distal $\left(D_{2}\right)$ ends of the aneurysm neck in the parent artery were measured on each image as shown in Fig $1 B$. The calculation is as follows:

$$
N R=\frac{C N D}{\left(\frac{D_{1}+D_{2}}{2}\right)}
$$

For NR measurements on 2D-DSA images, a line to measure the CND was first drawn across the aneurysmal neck. A line at the proximal end and a line at the distal end of the CND were then drawn in the parent vessel to measure $\mathrm{D}_{1}$ and $\mathrm{D}_{2}$, respectively (Fig $1 B)$.

\section{Other Morphology-Based Parameters}

Other common morphologic parameters calculated for each case were aneurysm size (size), neck diameter, aneurysm volume, aspect ratio, and size ratio. "Aspect ratio" is defined as the ratio of the aneurysm size to the neck diameter, and "size ratio" is defined as the ratio of aneurysm size to the parent vessel diameter. ${ }^{1-13}$ AView software was used to calculate these morphologic parameters to assess differences between the occluded and residual groups. ${ }^{14-16}$ Furthermore, as shown by Darsaut et al, ${ }^{17}$ the curvature of the aneurysm and parent vessel affects the occlusion outcome of FD-treated aneurysms. Therefore, we calculated the aneurysm angle and parent vessel angle for each aneurysm. ${ }^{11,17}$ To quantify aneurysm shapes in both groups, we calculated the following shape indices for each aneurysm: undulation index, nonsphericity index, ellipticity index, and bottleneck factor. ${ }^{11,12}$

\section{FD-Related Parameters}

Two FD-related parameters, metal coverage rate (MCR) and pore density, were calculated for each case to assess associations with occlusion status and the OsR. MCR quantifies the percentage area of the aneurysm neck covered by the FD wire struts, and pore density quantifies the number of FD pores per unit area at the neck plane. ${ }^{1,18,19}$ MCR and pore density could not be measured accurately from posttreatment images due to imaging artifacts after FD implantation. Therefore, virtual FD deployment was performed on each case to simulate clinical FD deployment and quantify MCR and pore density. We used an expansion-based in-house virtual stenting workflow to perform virtual FD deployment on these cases. ${ }^{20-22}$ MCR and pore density were quantified from the FD deployment results at the aneurysm neck. Details of the virtual stenting workflow, FD deployment, and quantification of the MCR and pore density are provided in the On-line Appendix.

FD deployments and subsequent MCR and pore density calculations are extremely variable and depend on the size of the device and the curvature and morphology of the artery. ${ }^{23,24}$ Therefore, to validate the MCR and pore density calculated after virtual stent placement, we performed experimental validation using physical deployment of FDs in 3 patient-specific aneurysm models fabricated using optically clear silicone. ${ }^{25}$ Validation results showed that the MCR and pore density from the virtual stenting workflow were within $10 \%$ of the physical
Table 1: Demographic and clinical information for patients in the occluded and residual groups

\begin{tabular}{lccc}
\hline \multicolumn{1}{c}{ Parameter } & Occluded & Residual & $\boldsymbol{P}$ Value \\
\hline Age (average \pm SE) (yr) & $57.6 \pm 2.4$ & $62.2 \pm 2.9$ & .28 \\
Female sex (No. of patients) & 37 & 15 & .12 \\
Hypertension (No. of patients) & 10 & 8 & .26 \\
Smoking (No. of patients) & 15 & 9 & .48 \\
\hline
\end{tabular}

Note:-SE indicates standard error.

deployment range for all 3 aneurysms. Details of validation analysis and results are included in the On-line Appendix.

Researchers involved in calculating the morphologic parameters (including the OsR and NR) and the FD-related parameters were blinded to the clinical outcome of the aneurysms.

\section{Statistical Analyses}

FD-treated aneurysms were dichotomized as "occluded" or "residual" based on the 6-month 2D-DSA images. Completely occluded aneurysms were included in the occluded group, and aneurysms with neck or dome remnants were included in the residual group. For statistical analysis, we performed the ShapiroWilk test to check for normal distribution of the continuous variables. A Mann-Whitney $U$ test (for non-normally distributed data) or a Student $t$ test (for normally distributed data) was used to distinguish differences in OsR, NR, size, neck diameter, volume, aspect ratio, size ratio, MCR, and pore density between the 2 groups. For categoric variables, a $\chi^{2}$ test was used to test statistically significant differences between the groups. All values were expressed as mean \pm standard error. Statistical significance was defined as a $P<.05$. Area under the receiver operating characteristic curve (area under the curve) and 95\% CI were used to assess the predictable power of statistically significant parameters. ${ }^{26}$ The optimal cutoff point was determined by the Youden Index (J statistic), ${ }^{27}$ which indicates the point in the receiver operating characteristic curve with maximum specificity and sensitivity. To determine whether the OsR and NR were related to the MCR and pore density, we performed linear regression analysis and defined correlation as $R^{2}>0.80$. Statistical analysis was performed using the commercial SPSS software package (Version 24.0; IBM, Armonk, New York).

\section{RESULTS}

A total of 63 aneurysms in 60 patients met the study inclusion criteria. At the time of FD treatment, 4 of 63 aneurysms were ruptured. At 6-month follow-up, 46 aneurysms were occluded, whereas 17 aneurysms had some residual contrast filling. No significant differences were found in age, sex, hypertension, or smoking status between the occluded and residual groups (Table 1). OsR was significantly higher in the residual group than in the occluded group $(0.58 \pm 0.03$ versus $0.35 \pm 0.02, P<.001$, Fig 2$)$. OsR values ranged from 0.13 to 0.66 and from 0.41 to 0.87 in the occluded and residual groups, respectively.

Apart from the OsR, the NR was the only morphologic parameter that was significantly higher in the residual group than the occluded group $(1.74 \pm 0.18$ versus $1.30 \pm 0.07, P=$ .02) (Table 2). Although values for size, neck diameter, volume, aspect ratio, and size ratio were higher in the residual group than in the occluded group, none of these parameters 


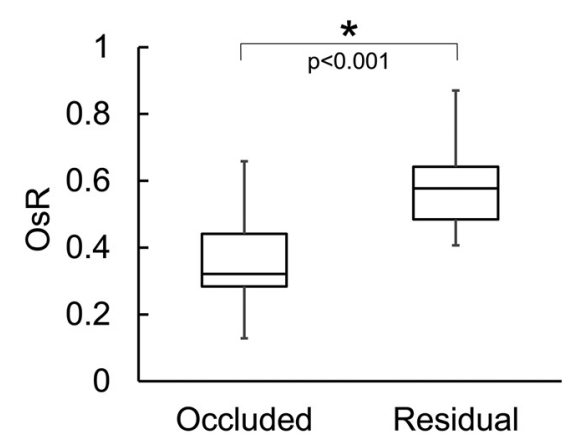

FIG 2. Box-and-whisker plot of the $\operatorname{OsR}(P<.001)$ shows a statistically significant difference in the OsR between the occluded and residual groups. The horizontal line within each box indicates the median, boundaries of the box indicate the 25th and 75th percentiles, and whisker bars represent the highest and lowest values of the OsR in each group.

Table 2: Aneurysmal morphologic and FD-related parameters in the occluded and residual groups ${ }^{a}$

\begin{tabular}{lccc}
\hline \multicolumn{1}{c}{ Parameter } & Occluded & Residual & $\boldsymbol{P}$ Value \\
\hline OsR & $0.35 \pm 0.02$ & $0.58 \pm 0.03$ & $<.001^{\mathrm{b}}$ \\
NR & $1.30 \pm 0.07$ & $1.74 \pm 0.18$ & $.02^{\mathrm{b}}$ \\
Size $(\mathrm{mm})$ & $5.6 \pm 0.6$ & $6.6 \pm 1.1$ & .29 \\
Neck diameter $(\mathrm{mm})$ & $4.67 \pm 0.26$ & $6.06 \pm 0.62$ & .06 \\
Aneurysm volume $\left(\mathrm{mm}^{3}\right)$ & $251.52 \pm 105.48$ & $502.75 \pm 239.77$ & .35 \\
AR & $1.01 \pm 0.08$ & $1.12 \pm 0.16$ & .53 \\
SR & $1.48 \pm 0.19$ & $2.00 \pm 0.43$ & .27 \\
UI & $0.06 \pm 0.01$ & $0.07 \pm 0.02$ & .77 \\
NSI & $0.23 \pm 0.01$ & $0.27 \pm 0.03$ & .43 \\
EI & $0.21 \pm 0.01$ & $0.24 \pm 0.02$ & .33 \\
BF & $1.26 \pm 0.07$ & $1.23 \pm 0.08$ & .15 \\
AA & $89.39 \pm 2.98$ & $89.32 \pm 2.63$ & .34 \\
PVA & $3.17 \pm 4.14$ & $4.61 \pm 6.27$ & .84 \\
MCR $(\%)$ & $27.46 \pm 0.51$ & $26.93 \pm 1.02$ & .64 \\
PD $\left(1 / \mathrm{mm}^{2}\right)$ & $28.35 \pm 0.86$ & $25.79 \pm 1.7$ & .19 \\
\hline
\end{tabular}

Note:-AA indicates aneurysm angle; AR, aspect ratio; BF, bottleneck factor; El, ellipticity index; $\mathrm{PD}$, pore density; $\mathrm{PVA}$, parent vessel angle; $\mathrm{SR}$, size ratio, $\mathrm{UI}$, undulation index; NSI, nonsphericity index.

${ }^{a}$ Values expressed as average \pm standard error.

${ }^{\mathrm{b}}$ Significant difference.

reached statistically significant differences. There was no statistical difference between aneurysm angle $(P=.34)$ and parent vessel angle $(P=.84)$ in the occluded and residual groups. In terms of shape indices, the undulation index, nonsphericity index, and ellipticity index were higher in the residual group, and bottleneck factor was higher in the occluded group. However, no shape index was significantly different in the occluded and residual groups. For FD-related parameters, the MCR and pore density were higher in the occluded group, but the differences between the groups were not statistically significant for either parameter (Table 2).

Figure 3 shows a comparison between the OsR and NR in the 2 groups (normalized by the values in the occluded group) (Fig $3 A$ ) and the receiver operating characteristic curve to assess their predictive powers (Fig $3 B$ ). There were larger differences between the normalized OsR in the occluded and residual groups compared with the normalized NR (Fig $3 A$ ). In the receiver operating characteristic analysis, the area under the curve for the OsR was $0.912(95 \% \mathrm{CI}, 0.838-0.985)$ and the NR was 0.707 (95\% CI, $0.558-0.856$ ) (Fig 3B). On the basis of the Youden Index (J statistic $)^{27}$ for maximal sensitivity and specificity, the optimum pre-

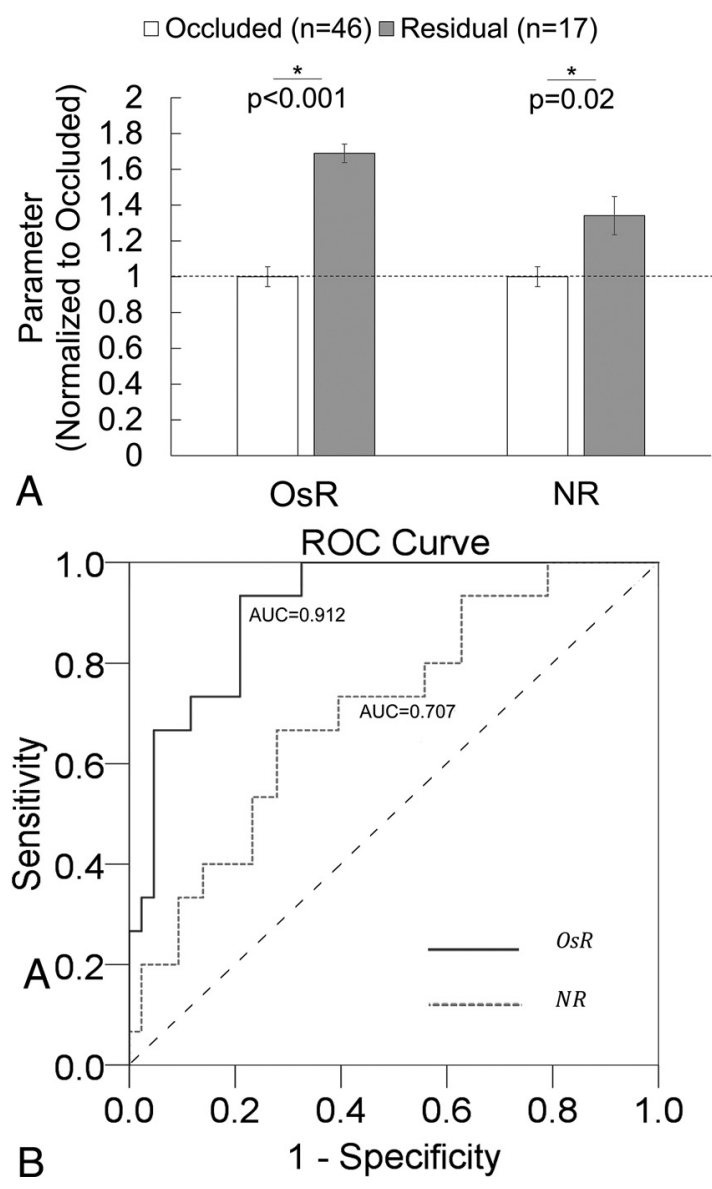

FIG 3. Comparison of the OsR and NR mean ( \pm standard error) normalized by the occluded group and receiver operating characteristic curves of the OsR and NR for occlusion status. $A$, Larger differences in the OsR between the occluded and residual groups $(P<.001) \mathrm{com}$ pared with the NR $(P=.02)$. $B$, Receiver operating characteristic curve ( $R O C$ ) of the OsR (solid line) and NR (dotted line) against the occlusion status, with an area under the curve of 0.912 for the OsR and 0.707 for the NR. The asterisk indicates statistically significant difference.

dictive cutoff to distinguish occluded-versus-residual cases occurred at $\mathrm{OsR}=0.46$ and $\mathrm{NR}=1.3$.

Linear regression analysis of FD-related parameters against the OsR and NR showed a statistically insignificant correlation between MCR and OsR, pore density and OsR, MCR and NR, and pore density and NR (Fig 4).

\section{DISCUSSION}

In this study, we sought to determine whether the relationship between aneurysm and parent artery morphology influences occlusion rates with FD treatment. We hypothesized that when a larger percentage of the parent vessel requires reconstruction and healing, the occlusion rate would fall. To test this hypothesis, we defined the novel metric, OsR, that captures this concept of the percentage of the parent vessel involved and found that a higher OsR correlates with aneurysm residual (incomplete occlusion) at 6 months. Our results suggest that aneurysms with higher OsR are less amenable to treatment with a single FD and may require alternate/adjunctive treatment paradigms. The predictive ability of the OsR was high, and previously described morphologic parameters (size, neck diameter, volume, aspect ratio, and size ratio) do not capture this complexity. 

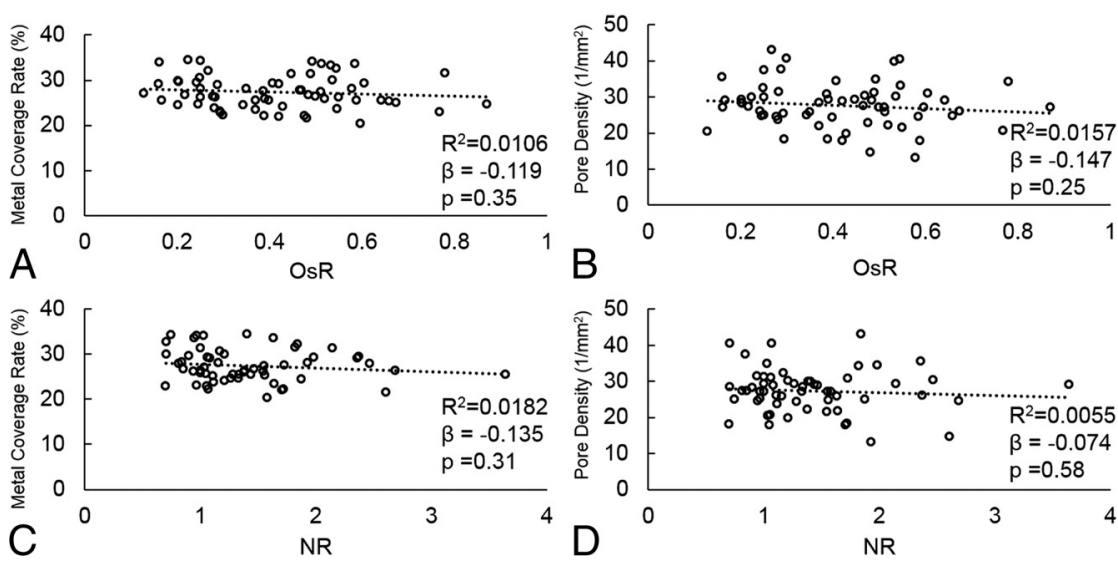

FIG 4. Linear regression analysis to test for correlation of the OsR and NR with FD parameters, MCR $(\%)(A$ and $C)$ and pore density $\left(1 / \mathrm{mm}^{2}\right)(B$ and $D)$. $A$ and $B, M C R\left(R^{2}=0.0106\right)$ and pore density $\left(R^{2}=0.0157\right)$ were independent of the OsR. $C$ and $D, M C R\left(R^{2}=0.0182\right)$ and pore density $\left(R^{2}=\right.$ $0.0055)$ were also independent of the NR. Corresponding $\beta$ and $P$ values are also provided.

\section{Large OsR Is Associated with Incompletely Occluded FD-Treated Aneurysms}

OsR, the ratio of the surface area of the aneurysm ostium to the remaining circumferential surface area of the corresponding parent artery, essentially quantifies the fraction of the area of an FD that will be exposed at the aneurysm ostium. An aneurysm ostium is defined by complex $3 \mathrm{D}$ curves, and OsR accurately quantifies this curvature and represents the patient-specific aneurysm defect relative to the parent artery. Higher OsR in our residual cases suggests that a larger proportion of the parent vessel (ie, a larger parent vessel defect) provided the inlet for blood flow into aneurysms in the residual group. This would lead to a higher flow rate into the aneurysmal sac, which poses more burden for flow diversion and hence less effective flowdiversion treatment using a single FD in these cases. This premise is confirmed by a recent study from our group in which aneurysms with a higher OsR had a significantly higher inflow rate into the aneurysmal sac both before and after FD implantation, and all 3 parameters (OsR, pretreatment inflow rate, and posttreatment inflow rate) were negatively correlated with treatment outcome. ${ }^{28}$ Thus, the OsR reflects flow-diversion effectiveness influenced by vascular morphology. It could potentially identify those aneurysms that are unsuitable for single-FD treatment.

A larger ostium has been correlated to the speed and degree of aneurysm occlusion after flow diversion in studies performed in animal models. ${ }^{10,29}$ For example, Chung et $\mathrm{al}^{29}$ deployed FDs in an elastase-induced rabbit aneurysm model and found that aneurysms with smaller ostia occluded faster than aneurysms with larger ostia. Additionally, Gentric et $\mathrm{al}^{10}$ deployed FDs in large and giant sidewall aneurysms in a canine model and found that aneurysms with larger ostia showed worse angiographic outcome than aneurysms with small ostia. To our knowledge, our study is the first to show a correlation between the aneurysm ostium and angiographic outcome of FD-treated aneurysms using clinical data. Our results mirror those of the previous animal studies, albeit we correlated angiographic imaging findings to OsR not just the surface area or length of the ostium. We postulate that the OsR, which represents how much of the parent vessel is covered by the aneurysm, may be a better indicator of outcome than the ostium area or length alone.

\section{NR as a Practical Surrogate for OsR}

For the OsR concept to be clinically useful, it must be readily obtained by clinicians when they are making treatment decisions. To this end, we devised the $\mathrm{NR}$ as a clinical surrogate for the OsR in predicting the success of flow diversion (NR area under the curve $=0.707 ; 95 \%$ CI, 0.558-0.856). Although the OsR had better performance, it is currently difficult to implement in the catheterization laboratory, whereas clinicians can easily measure neck diameter and parent vessel diameter to compute the NR (see the illustration in Fig 1B).

On the basis of the cutoff values of the OsR and NR, it can be interpreted that ICA aneurysms with OsR $\geq 0.46$ or $\mathrm{NR} \geq 1.3$ might not be amenable to treatment with a single FD. We suspect that in practice, clinicians will find that smaller OsR and NR values indicate that an aneurysm may occlude fully with a single FD. Conversely, larger values of the OsR and NR may indicate a need for alternative treatment strategies, such as additional FDs or adjunctive coils, ${ }^{30}$ to achieve similar rates of occlusion. Clinical studies have shown better success rates for FDs with adjunctive coils compared with FDs alone. ${ }^{31,32}$ Alternatively, for cases with a high OsR and NR, FD deployment techniques can change device properties. Catheter manipulations, such as "pushpull," during the deployment of an FD can locally compress and provide optimal metal coverage across the neck, and this may increase flow diversion away from the aneurysm, compared with normal FD-deployment technique. ${ }^{18,33}$ The push-pull technique enables localized compaction of the FD, increasing the MCR across the neck. ${ }^{33,34}$ However, prospective studies are required to assess the reliability of the OsR and NR in predicting the success of flow diversion.

\section{FD-Device Parameters Do Not Correlate with OsR or Angiographic Outcome}

In our study, we virtually deployed FDs in all aneurysm cases to investigate whether the device configuration in cases with larger OsRs may play a role in treatment outcome. On the basis of our results, we found no significant association between the OsR and the device-related metrics, MCR and pore density. This finding is in contrast to those of Gentric et al, ${ }^{10}$ who used FD deployment in silicone tubes to show larger deformation of the FD struts in aneurysms with larger ostia. They suggested that larger ostia modify the FD configuration, increasing porosity and potentiating ineffective flow diversion. However, we did not find any correlation of porosity with angiographic outcome or OsR. Further studies investigating how $\mathrm{FD}$-deployment configuration is related to poor clinical outcome are required.

\section{Limitations}

First, our analysis was performed on retrospectively collected data; a prospective study with a larger cohort is required to validate 
the power of the OsR and NR in predicting the outcome of FDtreated aneurysms. Second, due to the limited FD data base at our single center, we included only sidewall aneurysms located at the ICA and our results might not be applicable to sidewall aneurysms at other anatomic locations. Future studies of different aneurysm types at different anatomic locations are required to confirm our findings. Third, due to a steep learning curve for clinical FD deployment, deployment strategies have been optimized across time, resulting in higher success of FD treatment as operator experience increases. ${ }^{35}$ However, we did not consider operator experience in our study. Fourth, because the OsR and NR are independent on the FD device used, the effect of optimized FDdeployment strategies such as compacting the device at the aneurysm neck ${ }^{18}$ cannot be predicted by either the OsR or NR. Fifth, as demonstrated by Farzin et al, ${ }^{36}$ measurements of the MCR and pore density could be subjective and depend on the operator. Thus, our MCR and pore density measurements might not represent actual values but may provide a good estimate for each case, as shown by our experimental validation in the On-line Appendix.

\section{CONCLUSIONS}

We defined OsR, a novel metric that correlates with the occlusion status of flow-diverted sidewall aneurysms. We also defined a 2D surrogate, NR, as the ratio of aneurysm neck diameter to the parent vessel diameter. Retrospective analysis of 63 FD-treated aneurysms showed that a high OsR and NR are correlated with incomplete occlusion at 6-month follow-up. Common morphologic and device-related parameters (size, neck diameter, volume, aspect ratio, size ratio, MCR, and pore density) did not show an association with the angiographic outcome of FD-treated aneurysms. Receiver operating characteristic analysis showed the high predictive power of the OsR and NR to discriminate occluded and residual aneurysms. Prospective investigation is necessary to validate the OsR and NR as predictors of occlusion in FD-treated aneurysms.

\section{ACKNOWLEDGMENTS}

We thank Palak K. Patel for technical assistance; Paul H. Dressel, BFA, for preparation of the illustrations; and W. Fawn Dorr, BA, and Debra J. Zimmer for editorial assistance.

Disclosures: Vincent M. Tutino-OTHER RELATIONSHIPS: cofounder of Neurovascular Diagnostics. Elad I. Levy_UNRELATED: Board Membership: Stryker, NeXtGen Biologics, MEDX, Cognition Medical Systems, EndoStream Medical, Comments: on the advisory board, no money paid; Consultancy: Claret Medical, Gerson Lehman Group Consulting, Guidepoint Global, Imperative Care, Medtronic, Rebound Therapeutics, StimMed; Expert Testimony: I render medicolegal opinions as an expert witness for various attorneys; Payment for Lectures Including Service on Speakers Bureaus: Medtronic (formerly Covidien), Comments: honorarium for training and lectures; Stock/Stock Options: NeXtGen Biologics, Rapid Medical, Claret Medical, Cognition Medical Systems, Imperative Care, Rebound Therapeutics, StimMed, Three Rivers Medical Center, Comments: shareholder/ownership interest. Adnan $\mathrm{H}$. Siddiqui-UNRELATED: Consultancy: Amnis Therapeutics, Boston Scientific, Canon Medical Systems USA, Cerebrotech Medical Systems, Cerenovus, Claret Medical, Corindus, EndoStream Medical, Guidepoint Global, Imperative Care, Integra LifeSciences, Medtronic, MicroVention, Northwest University, Data and Safety Monitoring Board Chair for the HEAT Trial, Penumbra, Rapid Medical, Rebound Therapeutics, Silk Road Medical, StimMed, Stryker, Three Rivers Medical Center, VasSol, W.L. Gore \& Associates; Grants/Grants Pending: coinvestigator: National Institutes of Health/ National Institute of Neurological Disorders and Stroke 1R01NS091075, Virtual Intervention of Intracranial Aneurysms; Stock/Stock Options: Amnis Therapeutics,
Apama Medical, Blinktbi, Buffalo Technology, Cardinal Health, Cerebrotech Medical Systems, Claret Medical, Cognition Medical Systems, EndoStream Medical, Imperative Care, International Medical Distribution Partners, Rebound Therapeutics, Silk Road Medical, StimMed, Synchron, Three Rivers Medical Center, Viseon Spine; Other: National Principal Investigator/Steering Committees: Cerenovus LARGE trial and ARISE II trial, Medtronic SWIFT PRIME and SWIFT DIRECT trials, MicroVention FRED trial and CONFIDENCE study, MUSC POSITIVE trial, Penumbra 3D Separator Trial, COMPASS trial, INVEST trial. Jason M. Davies—RELATED: Grant: UB CTSA, Comments: KL2*; UNRELATED: Consultancy: Cerevenous, Medtronic*; Payment for Lectures Including Service on Speakers Bureaus: Penumbra; Stock/Stock Options: Rist Neurovascular, Inc. Hui Meng—RELATED: Grant: National Institutes of Health/National Institute of Neurological Disorders and Stroke, Comments: 5R01 NS091075-01*; UNRELATED: Employment: cofounder of Neurovascular Diagnostics. Gursant S. Atwal-UNRELATED: Consultancy: Imperative Care, Comments: consultant for a company about stroke care. *Money paid to the institution.

\section{REFERENCES}

1. D’Urso PI, Lanzino G, Cloft HJ, et al. Flow diversion for intracranial aneurysms: a review. Stroke 2011;42:2363-68 CrossRef Medline

2. Becske T, Kallmes DF, Saatci I, et al. Pipeline for uncoilable or failed aneurysms: results from a multicenter clinical trial. Radiology 2013; 267:858-68 CrossRef Medline

3. Becske T, Potts MB, Shapiro M, et al. Pipeline for uncoilable or failed aneurysms: 3-year follow-up results. J Neurosurg 2017;127:81-88 CrossRef Medline

4. Kallmes DF, Brinjikji W, Cekirge S, et al. Safety and efficacy of the Pipeline embolization device for treatment of intracranial aneurysms: a pooled analysis of 3 large studies. J Neurosurg 2017;127:775-80 CrossRef Medline

5. Kulcsár Z, Houdart E, Bonafé A, et al. Intra-aneurysmal thrombosis as a possible cause of delayed aneurysm rupture after flow-diversion treatment. AJNR Am J Neuroradiol 2011;32:20-25 CrossRef Medline

6. Siddiqui AH, Abla AA, Kan P, et al. Panacea or problem: flow diverters in the treatment of symptomatic large or giant fusiform vertebrobasilar aneurysms. J Neurosurg 2012;116:1258-66 CrossRef Medline

7. Turjman F, Massoud TF, Sayre J, et al. Predictors of aneurysmal occlusion in the period immediately after endovascular treatment with detachable coils: a multivariate analysis. AJNR Am J Neuroradiol 1998;19:1645-51 Medline

8. Johnston SC, Higashida RT, Barrow DL, et al; Committee on Cerebrovascular Imaging of the American Heart Association Council on Cardiovascular Radiology. Recommendations for the endovascular treatment of intracranial aneurysms: a statement for healthcare professionals from the Committee on Cerebrovascular Imaging of the American Heart Association Council on Cardiovascular Radiology. Stroke 2002;33:2536-44 CrossRef Medline

9. Mut F, Raschi M, Scrivano E, et al. Association between hemodynamic conditions and occlusion times after flow diversion in cerebral aneurysms. J Neurointerv Surg 2015;7:286-90 CrossRef Medline

10. Gentric JC, Darsaut TE, Makoyeva A, et al. The success of flow diversion in large and giant sidewall aneurysms may depend on the size of the defect in the parent artery. AJNR Am J Neuroradiol 2014;35: 2119-24 CrossRef Medline

11. Dhar S, Tremmel M, Mocco J, et al. Morphology parameters for intracranial aneurysm rupture risk assessment. Neurosurgery 2008; 63:185-96; discussion 196-97 CrossRef Medline

12. Raghavan ML, Ma B, Harbaugh RE. Quantified aneurysm shape and rupture risk. J Neurosurg 2005;102:355-62 Medline

13. Ujiie $\mathrm{H}$, Tamano $\mathrm{Y}$, Sasaki $\mathrm{K}$, et al. Is the aspect ratio a reliable index for predicting the rupture of a saccular aneurysm? Neurosurgery 2001;48:495-503; discussion 502-03 CrossRef Medline

14. Rajabzadeh-Oghaz H, Varble N, Davies JM, et al. Computer-assisted adjuncts for aneurysmal morphologic assessment: toward more precise and accurate approaches. Proc SPIE Int Soc Opt Eng 2017; 10134 CrossRef Medline

15. Xiang J, Antiga L, Varble N, et al. AView: an image-based clinical computational tool for intracranial aneurysm flow visualization

AJNR Am J Neuroradiol 40:288-94 Feb 2019 www.ajnr.org 
and clinical management. Ann Biomed Eng 2016;44:1085-96 CrossRef Medline

16. Xiang J, Varble N, Davies JM, et al. Initial clinical experience with AView: a clinical computational platform for intracranial aneurysm morphology, hemodynamics, and treatment management. World Neurosurg 2017;108:534-42 CrossRef Medline

17. Darsaut TE, Bing F, Salazkin I, et al. Flow diverters failing to occlude experimental bifurcation or curved sidewall aneurysms: an in vivo study in canines. J Neurosurg 2012;117:37-44 CrossRef Medline

18. Damiano R, Tutino V, Paliwal N, et al. Compacting a single flow diverter versus overlapping flow diverters for intracranial aneurysms: a computational study. AJNR Am J Neuroradiol 2017;38:603-10 CrossRef Medline

19. Wang K, Huang Q, Hong B, et al. Correlation of aneurysm occlusion with actual metal coverage at neck after implantation of flow-diverting stent in rabbit models. Neuroradiology 2012;54:607-13 CrossRef Medline

20. Paliwal N, Yu H, Damiano R, et al. Fast virtual stenting with vesselspecific initialization and collision detection. In: Proceedings of the ASME International Design Engineering Technical Conferences and Computers and Information in Engineering Conference, Buffalo, New York. August 17-20, 2014; V003T12A14-V03T12A14

21. Paliwal N, Yu H, Xu J, et al. Virtual stenting workflow with vesselspecific initialization and adaptive expansion for neurovascular stents and flow diverters. Comput Methods Biomech Biomed Engin 2016;19:1423-31 CrossRef Medline

22. Larrabide I, Kim M, Augsburger L, et al. Fast virtual deployment of self-expandable stents: method and in vitro evaluation for intracranial aneurysmal stenting. Med Image Anal 2012;16:721-30 CrossRef Medline

23. Bing F, Darsaut TE, Salazkin I, et al. Stents and flow diverters in the treatment of aneurysms: device deformation in vivo may alter porosity and impact efficacy. Neuroradiology 2013;55:85-92 CrossRef Medline

24. Makoyeva A, Bing F, Darsaut T, et al. The varying porosity of braided self-expanding stents and flow diverters: an experimental study. AJNR Am J Neuroradiol 2013;34:596-602 CrossRef Medline

25. Paliwal N, Damiano RJ, Varble NA, et al. Methodology for compu- tational fluid dynamic validation for medical use: application to intracranial aneurysm. J Biomech Eng 2017;139 CrossRef Medline

26. Hanley JA, McNeil BJ. The meaning and use of the area under a receiver operating characteristic (ROC) curve. Radiology 1982;143: 29-36 CrossRef Medline

27. Youden WJ. Index for rating diagnostic tests. Cancer 1950;3:32-35 CrossRef

28. Paliwal N, Jaiswal P, Tutino VM, et al. Outcome prediction of intracranial aneurysm treatment by flow diverters using machine learning. Neurosurg Focus 2018;45:E7 CrossRef Medline

29. Chung B, Mut F, Kadirvel R, et al. Hemodynamic analysis of fast and slow aneurysm occlusions by flow diversion in rabbits. J Neurointerv Surg 2015;7:931-35 CrossRef Medline

30. Damiano RJ, Ma D, Xiang J, et al. Finite element modeling of endovascular coiling and flow diversion enables hemodynamic prediction of complex treatment strategies for intracranial aneurysm. J Biomech 2015;48:3332-40 CrossRef Medline

31. Lin N, Brouillard AM, Krishna C, et al. Use of coils in conjunction with the Pipeline Embolization Device for treatment of intracranial aneurysms. Neurosurgery 2015;76:142-49 CrossRef Medline

32. Nossek E, Chalif DJ, Chakraborty S, et al. Concurrent use of the Pipeline Embolization Device and coils for intracranial aneurysms: technique, safety, and efficacy. J Neurosurg 2015;122:904-11 CrossRef Medline

33. Xiang J, Ma D, Snyder KV, et al. Increasing flow diversion for cerebral aneurysm treatment using a single flow diverter. Neurosurgery 2014;75:286-94; discussion 294 CrossRef Medline

34. Ma D, Xiang J, Choi $\mathrm{H}$, et al. Enhanced aneurysmal flow diversion using a dynamic push-pull technique: an experimental and modeling study. AJNR Am J Neuroradiol 2014;35:1779-85 CrossRef Medline

35. Jabbour P, Chalouhi N, Tjoumakaris S, et al. The Pipeline Embolization Device: learning curve and predictors of complications and aneurysm obliteration. Neurosurgery 2013;73:113-20; discussion 120 CrossRef Medline

36. Farzin B, Brosseau L, Jamali S, et al. Flow diverters: inter and intrarater reliability of porosity and pore density measurements. $\mathrm{J} \mathrm{Neu}$ rointerv Surg 2015;7:734-39 CrossRef Medline 